CORRIGENDUM

doi:10.1038/nature08125

\title{
Millennial-scale trends in west Pacific warm pool hydrology since the Last Glacial \\ Maximum
}

Judson W. Partin, Kim M. Cobb, Jess F. Adkins, Brian Clark

\& Diego P. Fernandez

\section{Nature 449, 452-455 (2007)}

A recalibration of the Caltech ${ }^{236} \mathrm{U}$ and ${ }^{229} \mathrm{Th}$ spike has determined that the original spike value used for the stalagmite chronologies yielded U-Th ages that were too old by a margin of $\sim 2-3 \%$. U-Th ages and subsequent age models have been recalculated using the new spike value for all stalagmites. The new age models alter the absolute timing of certain events, but do not alter any major conclusions of the original manuscript. The highest $\delta^{18} \mathrm{O}$ values (inferred driest conditions) now occur at $16.0 \pm 0.3 \mathrm{kyr}$ ago. A late deglacial $\delta^{18} \mathrm{O}$ plateau in the Borneo stalagmite records is now centred at $13.0 \pm 0.2 \mathrm{kyr}$ ago. The lowest $\delta^{18} \mathrm{O}$ values (inferred wettest conditions) now occur at $5.0 \pm 0.1 \mathrm{kyr}$ ago. Examples of original and adjusted dates, respectively, at $5 \mathrm{kyr}$ intervals are as follows: 5280 versus 5141 (SSC01); 10581 versus 10293 (SSC01); 15673 versus 15231 (BA04); 20937 versus 20322 (BA04); and 26387 versus 25602 (SCH02). Revised chronologies are available at: ftp://ftp.ncdc.noaa.gov/pub/data/paleo/speleothem/ pacific/gunung-buda2007.xls 